\title{
Substance Use Disorders in Men Presenting to a Psychosexual Clinic
}

\author{
Ravi Philip Rajkumar \\ Department of Psychiatry, Jawaharlal Institute of Postgraduate Medical Education and Research (JIPMER), \\ Dhanvantari Nagar, Pondicherry 605 006, India
}

Correspondence should be addressed to Ravi Philip Rajkumar; ravi.psych@gmail.com

Received 12 November 2013; Accepted 16 December 2013; Published 6 January 2014

Academic Editors: T. G. Brown, P. Mannelli, C. S. Myers, and S. Rahman

Copyright (C) 2014 Ravi Philip Rajkumar. This is an open access article distributed under the Creative Commons Attribution License, which permits unrestricted use, distribution, and reproduction in any medium, provided the original work is properly cited.

\begin{abstract}
Introduction. Substance use disorders (SUDs) are commonly associated with a variety of psychiatric disorders. Community-based studies have found a significant association between SUDs and sexual dysfunction in men, with a possible causal relation in the case of nicotine. Methods. The case records of 105 men presenting to a clinic for patients with psychosexual disorders were reviewed. Men with and without comorbid SUDs were compared in terms of demographic, clinical, and familial variables. Results. 25 of the 105 men $(23.8 \%)$ had a lifetime diagnosis of SUD, and 19 (18.1\%) had a current SUD. The commonest substances involved were nicotine $(n=21,20 \%)$ and alcohol $(n=9,9.5 \%)$. Men with comorbid SUDs were more likely to report a family history of substance dependence, particularly alcoholism. Single men with SUDs were more likely to have a comorbid mood disorder. Conclusion. SUDs, particularly nicotine and alcohol use disorders, are common comorbidities in patients with psychosexual disorders. Identifying and treating these disorders in this population are important aspects of management.
\end{abstract}

\section{Introduction}

Substance use disorders (SUDs) are a global health problem which present in a variety of clinical settings. Substance use may complicate an underlying medical or psychiatric disorder and can also lead to medical or psychological morbidity in its own right. High rates of substance use have been reported in patients with psychiatric syndromes such as schizophrenia [1], mood disorders [2, 3], and anxiety disorders [3]. Patients with both conditions, sometimes referred to as "dual-diagnosis" patients, have been found to have more severe symptoms and poorer outcomes $[1,4]$.

Psychosexual disorders, also termed psychogenic sexual disorders, are dysfunctions of the sexual response cycle that cause impaired sexual performance and distress to affected patients and their partners. These disorders can affect any phase of the sexual response cycle. The commonest sexual disorders seen in male patients are premature ejaculation [5] and erectile dysfunction [6]. Earlier studies have reported significant rates of problematic substance use in men with sexual disorders [7-9], but this association has been less well studied than in patients with other mental disorders, and its causal significance is unclear. A consistent association between erectile dysfunction and tobacco use has been found $[7,9]$, but the effects of alcohol use on sexual dysfunction are less clear [10]. However, this association has not been systematically examined in the Indian context. In the current study, we retrospectively examined the rates of substance use, abuse, and dependence in young and middle-aged South Indian men presenting to an outpatient clinic for psychosexual disorders.

\section{Materials and Methods}

The case records of 105 male patients who attended the Marital and Psychosexual Disorders (MAPS) Clinic at the Jawaharlal Institute of Postgraduate Medical Education and Research (JIPMER) between January 2011 and October 2013 were reviewed. JIPMER is a tertiary care institute located in Pondicherry, South India. Alcohol use disorders are a significant problem in Pondicherry, which was a further motivation for conducting this study. 
The majority of clinic attenders are young men, both married and single. Patients are referred to the clinic either by self-referral or from other departments in JIPMER, particularly general surgery and urology. At initial presentation, a brief assessment is made by a trained psychiatrist, and an appointment is given for a detailed evaluation in the MAPS clinic. On the day of this appointment, patients are evaluated using a semistructured interview to elicit a sexual history as well as details of medical and psychiatric comorbidity, family history of mental illness, and early childhood experiences. All interviews are conducted by psychiatry residents, and diagnoses are made according to ICD-10 clinical guidelines after review by a consultant. Following diagnosis, patients received psychological interventions, including education and behaviour therapy. Pharmacotherapy in the form of antidepressants and anxiolytics was used for the management of comorbid anxiety and depression, and the short-acting serotonin uptake inhibitor dapoxetine was used in selected patients with premature ejaculation.

Statistical analyses were carried out using the WinPEpi version of the OpenEpi program. All tests were two-tailed and a significance level of 0.05 was considered statistically significant.

\section{Results}

The sample consisted of 105 men. Of these, 25 (23.8\%) had a lifetime diagnosis of a substance use disorder; a further 7 (6.7\%) had used alcohol or nicotine but were not dependent on them. Of the 25 with an identified substance use disorder, 3 only had a harmful use pattern without dependence; all of these three men were using alcohol. The remaining 22 (21\%) fulfilled criteria for substance dependence: 21 had nicotine dependence, and 6 had alcohol dependence. Five men had both nicotine and alcohol dependence. One patient had harmful use of benzodiazepines, and one reported harmful use of cannabis. Among those men with a history of alcoholism $(n=6)$, the mean age at onset of dependence was $22.8 \pm 3.11$ years; three of these men $(50 \%)$ had an early $(<25$ years) onset. Only one of the men with alcohol dependence had a family history of alcoholism.

Of these 25 men, 19 (18.1\%) fulfilled ICD-10 criteria for current harmful use or dependence: 17 with nicotine dependence and two with alcohol dependence, one with harmful use of alcohol and one with harmful use of benzodiazepines. The two men with current alcohol dependence also had active nicotine dependence. The remaining six had discontinued substance use prior to receiving a diagnosis of sexual dysfunction.

When patients with comorbid substance use were compared with those without, the two groups were comparable on most variables, including age, duration of illness, types of sexual dysfunction, comorbid conditions, and early childhood adversity. However, men with comorbid substance use were more likely to have a family history of substance dependence (alcohol or nicotine) in a first-degree relative (14/25 versus $\left.23 / 80 ; \chi^{2}=6.198, P=0.013\right)$. This association held good even when only family histories of alcoholism were considered
TABLE 1: Clinical profile of men with psychosexual disorders, with (SUD+) and without (SUD-) comorbid substance use disorders.

\begin{tabular}{|c|c|c|}
\hline Variable & $\begin{array}{l}\text { SUD+ } \\
(n=25)^{*}\end{array}$ & $\begin{array}{l}\text { SUD- } \\
(n=80)^{*}\end{array}$ \\
\hline Age & $29.08(6.1)$ & $28.8(7.49)$ \\
\hline $\begin{array}{l}\text { Duration of sexual disorder (in } \\
\text { years) }\end{array}$ & $2.71(3.09)$ & $3.2(3.01)$ \\
\hline \multicolumn{3}{|l|}{ Marital status } \\
\hline Single & $15(60 \%)$ & $51(63.75 \%)$ \\
\hline Married & $10(40 \%)$ & $29(36.25 \%)$ \\
\hline \multicolumn{3}{|l|}{ Psychosexual diagnosis } \\
\hline Erectile dysfunction & $13(52 \%)$ & $30(37.5 \%)$ \\
\hline Premature ejaculation & $6(24 \%)$ & $22(27.5 \%)$ \\
\hline Dhat syndrome & $11(44 \%)$ & $37(46.25 \%)$ \\
\hline Impulse control disorder NOS & - & $1(1.25 \%)$ \\
\hline Lack of sexual desire & - & $1(1.25 \%)$ \\
\hline Ego-dystonic homosexuality & - & $2(2.5 \%)$ \\
\hline Comorbid mood disorder & $5(20 \%)$ & $10(12.5 \%)$ \\
\hline Depression & $2(8 \%)$ & $6(7.5 \%)$ \\
\hline Dysthymia & $2(8 \%)$ & $3(3.75 \%)$ \\
\hline Recurrent brief depression & - & $1(1.25 \%)$ \\
\hline Mixed anxiety depression & $1(4 \%)$ & - \\
\hline Comorbid anxiety disorder & $4(16 \%)$ & $16(20 \%)$ \\
\hline Generalized anxiety disorder & $3(12 \%)$ & $2(2.5 \%)$ \\
\hline $\begin{array}{l}\text { Anxious-avoidant personality } \\
\text { disorder }\end{array}$ & $1(4 \%)$ & $12(15 \%)$ \\
\hline Specific phobia & - & $1(1.25 \%)$ \\
\hline $\begin{array}{l}\text { Anxiety disorder not otherwise } \\
\text { specified }\end{array}$ & - & $1(1.25 \%)$ \\
\hline \multicolumn{3}{|l|}{$\begin{array}{l}\text { Family history of mood } \\
\text { disorder/suicide }\end{array}$} \\
\hline Mood disorder & - & $6(7.5 \%)$ \\
\hline Suicide & $1(4 \%)$ & $4(5 \%)$ \\
\hline $\begin{array}{l}\text { Family history of substance } \\
\text { dependence }\end{array}$ & $14(56 \%)$ & $23(28.75 \%)^{* *}$ \\
\hline Alcohol & $11(44 \%)$ & $18(22.5 \%)^{* * *}$ \\
\hline Nicotine & $3(12 \%)$ & $5(6.25 \%)$ \\
\hline $\begin{array}{l}\text { Parental breakup or discord during } \\
\text { childhood }\end{array}$ & $6(24 \%)$ & $16(20 \%)$ \\
\hline Marital disharmony & $3(30 \%)^{\#}$ & $16(55.18 \%)^{\$}$ \\
\hline \multicolumn{3}{|c|}{$\begin{array}{l}{ }^{*} \text { All figures are given as mean (standard deviation) or frequency (percent- } \\
\text { age). }\end{array}$} \\
\hline
\end{tabular}

$\left(11 / 25\right.$ versus $\left.18 / 80 ; \chi^{2}=4.404, P=0.036\right)$. Anxious-avoidant personality was more common in men without substance use disorders ( $15 \%$ versus $4 \%$ ), but this difference was not statistically significant (Table 1).

When the subgroup with active substance use alone ( $n$ $=19$ ) was compared with the group without substance use disorders, they were also significantly more likely to have a family history of substance dependence (12/19 versus $23 / 80$; 
$\left.\chi^{2}=7.953, P=0.005\right)$ or alcoholism in particular (9/19 versus $\left.18 / 80 ; \chi^{2}=4.787, P=0.029\right)$. However, they did not differ on any other clinical or demographic variable, including the type of sexual dysfunction experienced.

Separate analyses were then conducted to compare the profiles of single and married men with and without substance use disorders. Among single men, patients with comorbid substance use disorders were more likely to suffer from a comorbid mood disorder ( $5 / 15$ versus $4 / 51 ; \chi^{2}=6.395$, $P=0.011)$ and were more likely to have a family history of alcoholism (9/15 versus 11/51; $\left.\chi^{2}=8.106, P=0.004\right)$ than those without substance use disorders; the two groups were comparable in other respects.

Among married men, patients with comorbid substance use disorders were less likely to report infertility as a precipitating or aggravating factor for their sexual dysfunction (none out of 10 versus $9 / 29 ; \chi^{2}=4.034, P=0.045$ ); however, they did not differ from married men without substance use disorder on any other clinical or demographic variable. Nonsubstance users were numerically more likely to report marital disharmony (55.16\% against 30\% of married substance users), but this difference did not reach statistical significance.

\section{Discussion}

The rate of comorbid substance use disorders in men with psychosexual disorders was $23.8 \%$; in $21 \%$, this amounted to dependence. These rates are slightly higher than those reported for mood or anxiety disorders in general [3] but lower than those reported for schizophrenia [1] or bipolar disorder [2], and they are comparable to the rates of regular smoking (27.2\%) reported in Australian men with erectile dysfunction [9]. This suggests that substance use disorders may be an important comorbidity in men with sexual dysfunction and should be screened for and addressed in its own right.

In this sample, nicotine and alcohol were the most common substances abused. As these substances are licit and freely available, they are commonly used by young men in India. In contrast, the use of other drugs such as benzodiazepines and cannabis was infrequent in our patients. This pattern is consistent with epidemiological research on the relative frequencies of various substance use disorders in India [11]. The rates reported in our patients are somewhat lower than those reported from deaddiction centres in India [12], though they are higher than those documented in the general population [13].

The most significant difference noted between men with and without substance use disorders in this study was the presence of a family history of substance dependence, particularly alcoholism, in the former group. This is in line with current evidence on the genetics of alcoholism and nicotine dependence [12]. Further research is needed to examine the possibility that substance use disorders and psychosexual disorders may arise from a shared genetic liability.

Single men with substance use and psychosexual disorders were more likely to suffer from mood disorders in our study. This may reflect the well-documented association between depression and substance use [13, 14]. Caution is required in managing depression in this population, as antidepressants can themselves worsen sexual dysfunction in some patients [15].

As this study was retrospective, a causal association between substance use disorders and sexual dysfunction could not be established. Moreover, the "control" group consisted of men with a primary diagnosis of sexual dysfunction, making meaningful comparisons difficult. Current evidence suggests that smoking cessation can improve sexual dysfunction in men [16]. Though a meta-analytic review found that the association between alcohol use and erectile dysfunction was inconsistent [10], an Indian study found a significant link between alcohol dependence and sexual disorders [17]. Managing the comorbid substance use disorder in these patients may therefore lead to resolution of the patient's sexual dysfunction.

The above results are subject to several limitations. Diagnoses were made using the ICD-10 clinical guidelines and depended on clinical skill rather than the use of a structured diagnostic interview. The retrospective design limits the generalizations that can be made from our findings. And finally, the study sample, which was drawn from a clinic for psychosexual disorders, may not accurately represent the young and middle-aged male population.

\section{Conclusion}

Substance use disorders are a common comorbid diagnosis in men with psychosexual disorders. In these patients, substance use disorders tend to run in families and may be associated with higher rates of mood disorder in single men. These findings have clear implications when assessing and treating men with sexual disorders. Further prospective hospital and community-based studies are needed to obtain a better estimate of the magnitude and correlates of this problem.

\section{Conflict of Interests}

The author declares that there is no conflict of interests regarding the publication of this paper.

\section{References}

[1] I. L. Fowler, V. J. Carr, N. T. Carter, and T. J. Lewin, "Patterns of current and lifetime substance use in schizophrenia," Schizophrenia Bulletin, vol. 24, no. 3, pp. 443-455, 1998.

[2] S. L. McElroy, L. L. Altshuler, T. Suppes et al., "Axis I psychiatric comorbidity and its relationship to historical illness variables in 288 patients with bipolar disorder," American Journal of Psychiatry, vol. 158, no. 3, pp. 420-426, 2001.

[3] B. F. Grant, F. S. Stinson, D. A. Dawson et al., "Prevalence and co-occurrence of substance use disorders and independent mood and anxiety disorders," Archives of General Psychiatry, vol. 61, no. 8, pp. 807-816, 2004.

[4] J. Rachbeiscl, J. Scott, and L. Dixon, "Co-occurring severe mental illness and substance use disorders: a review of recent research," Psychiatric Services, vol. 50, no. 11, pp. 1427-1434, 1999. 
[5] C. G. McMahon, "Premature ejaculation," Indian Journal of Urology, vol. 23, no. 2, pp. 97-108, 2007.

[6] J. S. Simons and M. P. Carey, "Prevalence of sexual dysfunctions: results from a decade of research," Archives of Sexual Behavior, vol. 30, no. 2, pp. 177-219, 2001.

[7] A. Martin-Morales, J. J. Sanchez-Cruz, I. S. de Tejada, L. Rodriguez-Vela, J. F. Jimenez-Cruz, and R. Burgos-Rodriguez, "Prevalence and independent risk factors for erectile dysfunction in Spain: results of the epidemiologia de la disfuncion erectil masculina study," Journal of Urology, vol. 166, no. 2, pp. 569-574, 2001.

[8] V. Kupelian, A. B. Araujo, G. R. Chiu, R. C. Rosen, and J. B. McKinlay, "Relative contributions of modifiable risk factors to erectile dysfunction: results from the Boston Area Community Health (BACH) Survey," Preventive Medicine, vol. 50, no. 1-2, pp. 19-25, 2010.

[9] C. Millett, C. Rissel, A. Smith et al., "Smoking and erectile dysfunction: findings from a representative sample of Australian men," Tobacco Control, vol. 15, no. 2, pp. 136-139, 2006.

[10] J. Y. W. Cheng, E. M. L. Ng, R. Y. L. Chen, and J. S. N. Ko, "Alcohol consumption and erectile dysfunction: meta-analysis of population-based studies," International Journal of Impotence Research, vol. 19, no. 4, pp. 343-352, 2007.

[11] D. Mohan, A. Chopra, and H. Sethi, "Incidence estimates of substance use disorders in a cohort from Delhi, India," Indian Journal of Medical Research, vol. 115, pp. 128-135, 2002.

[12] R. Ray and A. Chopra, "Monitoring of substance abuse in India-initiatives \& experiences.," Indian Journal of Medical Research, vol. 135, pp. 806-808, 2012.

[13] V. Benegal, "India: alcohol and public health," Addiction, vol. 100, no. 8, pp. 1051-1056, 2005.

[14] I. R. Schlaepfer, N. R. Hoft, and M. A. Ehringer, "The genetic components of alcohol and nicotine co-addiction: from genes to behavior," Current Drug Abuse Reviews, vol. 1, no. 2, pp. 124134, 2008.

[15] K. C. Young-Wolff, K. S. Kendler, N. D. Sintov, and C. A. Prescott, "Mood-related drinking motives mediate the familial association between major depression and alcohol dependence," Alcoholism, vol. 33, no. 8, pp. 1476-1486, 2009.

[16] A. C. Edwards, H. H. Maes, N. L. Pedersen, and K. S. Kendler, "A population-based twin study of the genetic and environmental relationship of major depression, regular tobacco use and nicotine dependence," Psychological Medicine, vol. 41, no. 2, pp. 395-405, 2011.

[17] A. L. Montejo, G. Llorca, J. A. Izquierdo, and F. RicoVillademoros, "Incidence of sexual dysfunction associated with antidepressant agents: a prospective multicenter study of 1022 outpatients," Journal of Clinical Psychiatry, vol. 62, supplement 3, pp. 10-21, 2001. 


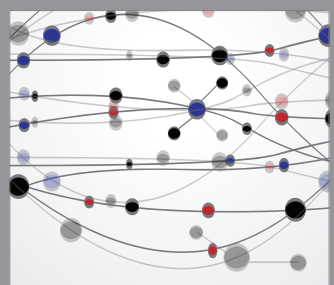

The Scientific World Journal
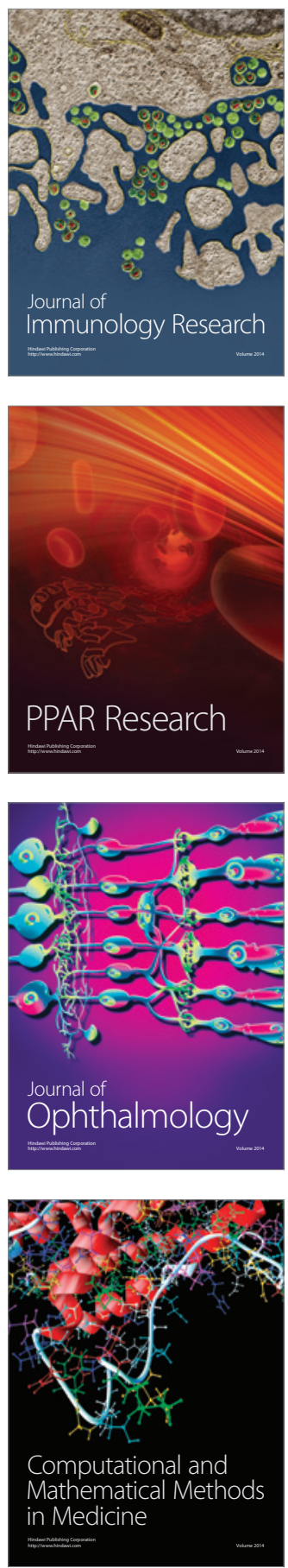

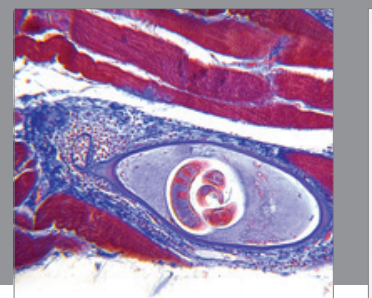

Gastroenterology

Research and Practice
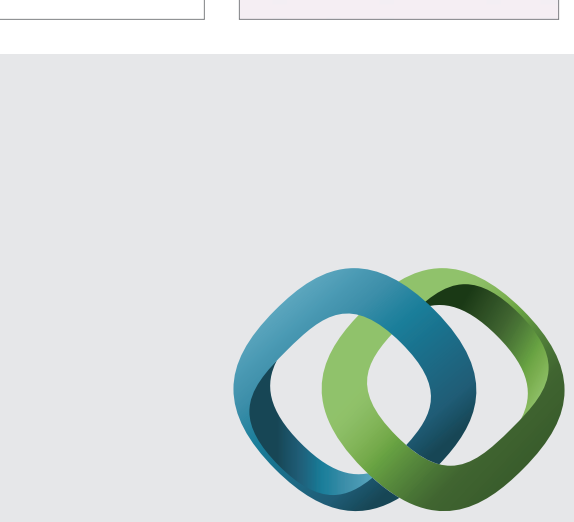

\section{Hindawi}

Submit your manuscripts at

http://www.hindawi.com
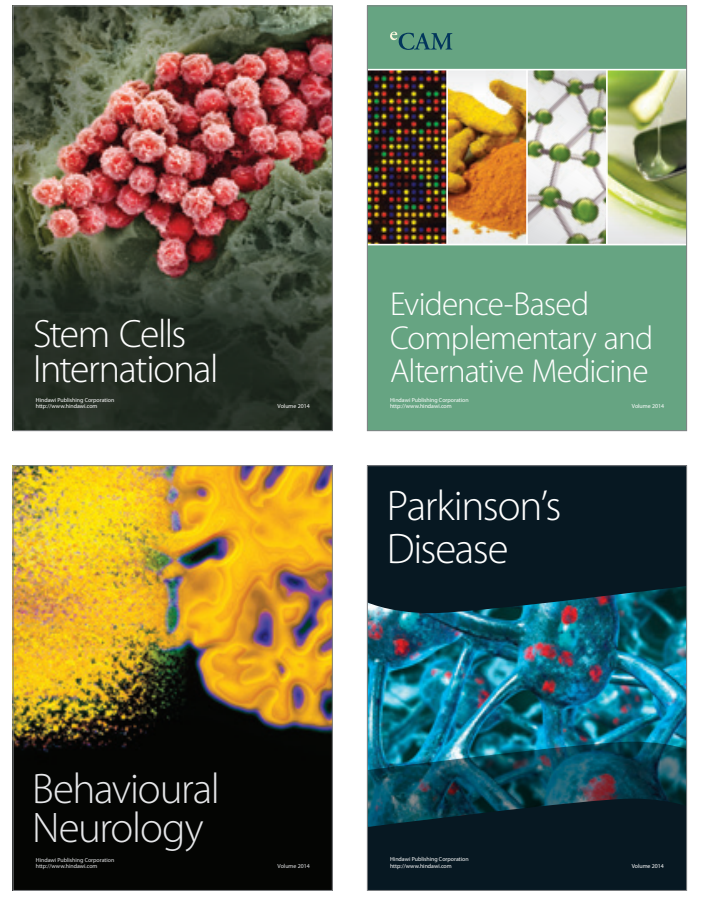


Disease Markers
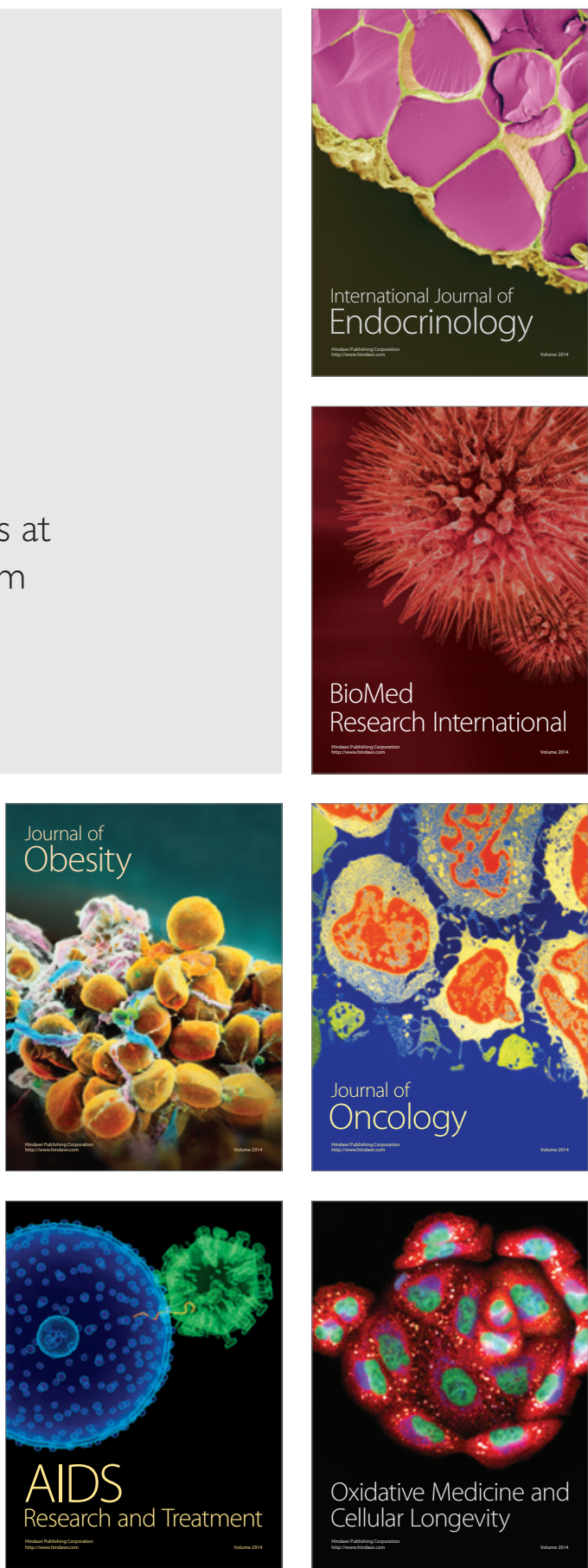